\title{
Molecular Mechanisms of Polyhostality in Relation to Emerging Infectious Diseases
}

\author{
Svetlana Ermolaeva* \\ Gamaleya Institute of Epidemiology and Microbiology, Gamaleya st. 18, Moscow 123098, Moscow, Russia
}

Received: January 14, 2015; Accepted: January 23, 2015; Published: February 03, 2015

*Corresponding author: Gamaleya Institute of Epidemiology and Microbiology, Gamaleya st. 18, Moscow 123098, Moscow, Russia, Tel: +7-909-939-9612; E-mail: drermolaeva@mail.ru

\begin{abstract}
Introduction of ecological approaches into medical microbiology has changed our view on infectious diseases. The recognition of a pathogen as a part of the biotic environment is particularly important for emerging diseases. When an emerging infection agent enters the environment of a human body for the first time, it undergoes a harsh transition, which is totally different from slow co-evolution. The review considers mechanisms that provide survival and multiplication in a previously unfamiliar environment and particularly polyhostality that can be defined as the capacity of a microbe to colonize several species belonging to different taxa. The molecular basis of polyhostality relies on conservatism of eukaryotic cell structures that provides successful interactions of bacterial factors developed in the course of evolution in the natural habitat with human targets. While mechanisms of polyhostality are at the beginning of the study, they are of great importance for comprehension of infection pathology and development of novel methods of epidemiological monitoring.
\end{abstract}

Keywords: Evolution of pathogenic bacteria; Microbial ecology; Emerging infectious diseases; Virulence factors

In the last years, our main anthropocentric view of infectious diseases as a directional attack of an armed with virulence factors microbe on humans has been changing to the recognition of pathogens as an integral part of the biotic environment [1]. This recognition essentially depends on introduction of ecological approaches into medical microbiology and infectious disease studies and deepens our understanding of interactions between humans and pathogenic species at different levels [2,3].

The relationships between pathogens and their natural environment are particularly important for understanding molecular biology, evolution and epidemiology of emerging infections. An emerging infection is defined as an infectious disease that has newly appeared or that has been known for some time but is rapidly increasing in incidence or geographic range [4]. It is the nature that supplies new infectious agents that originate in soil or water ecosystems. Human activities are the main cause of the emergence of new pathogens as significant health issues $[5,6]$. Different factors such as human appearance in previously pristine regions, transformation of natural habitats due to agricultural and industrial development, an enlarged scale of trade flow result in transmission of multiple microbial species to a new environment and after all put them in touch with a human organism. Then, instead of slow evolution, when members of a stable consortium living in persistent symbiosis continually adapt to each other, the harsh transition takes place and the new environment such a human body requires an immediate response.

The general ecological mechanism that provides species survival and multiplication in a previously unfamiliarenvironment and is known as pre adaptation appears to be involved in the phenomenon of emerging infections [7]. Living in their natural environment, causative agents of emerging infections might be wild mammal pathogens or be carried asymptomatically by wild animals or be rather microbial community members than true pathogens. Their pre adaptation becomes apparent in the form of polyhostality. The term polyhostality came from descriptions of natural foci of infections where it means that the foci are supported by multiple hosts. Latter, the term polyhostality was widening to describe the capacity of a microbe to colonize several species belonging to different taxa or even to different kingdoms [8]. The Gram-negative bacterium L. pneumophila is a best studied example when adaptation for survival in protozoa provides virulence for humans [9]. The rhizosphere inhabitant Burkholderia cenocepacia was shown to establish chronic infections in immunocompromised patients. Studies of the last years demonstrated that it is a capacity to adapt for a host niche but not host cell or tissue damage that contributes in $B$. cenocepacia infection in humans [10]. The better known as a food born pathogen, Y. pseudotuberculosis effectively colonizes plants [11]. Another food born pathogen, the Gram-positive bacterium L. monocytogenes, was isolated from a wild spectrum of wildlife including mammals, birds and fish and seems to be a widely spread member of soil ecosystems $[12,13]$.

From the molecular point of view, the polyhostality is provided by a capacity of bacterial factors developed in the course of evolution in the natural habitat to interact with human targets. Such factors may play similar roles in natural hosts and in human infection or gain additional functions. L. pneumophila factors involved in intracellular replication within its natural hosts amoeba and ciliated protozoa were shown to play a similar role in macrophage infection [14]. The thiol-dependent hemolysin 
L. monocytogenes Listeriolysin 0 (LLO), which is required for intracellular survival and apoptosis induction in lymphocytes in the course of infection in humans, promotes bacterial survival and growth in the presence of bacteriovorus ciliate T. pyriformis and is responsible for L. monocytogenes toxicity for protozoa and induction of protozoan encystment [15]. The conservatism in eukaryotic cell structure underlies the molecular basis of polyhostality.

The molecular mechanisms of polyhostality are at the beginning of the study. Meanwhile they are important for a systematical understanding of human infection pathology. When coupled with "omics" methods, ecological approaches in pathogenic studies will provide a novel basement for future methods of epidemiological monitoring.

\section{Acknowledgement}

I thank Dr. V.I. Pushkareva and all other members of the lab for discussions. The work of the author is supported by RFBI (grant 14-04-00486)

\section{References}

1. Vayssier-Taussat M, Albina E, Citti C, Cosson JF, Jacques MA, Lebrun $\mathrm{MH}$, et al. Shifting the paradigm from pathogens to pathobiome: new concepts in the light of meta-omics. Front Cell Infect Microbiol, 2014; 4: 29. doi: 10.3389/fcimb.2014.00029.

2. Litvin VYu, Gintsburg AL, Pushkareva VI, Romanova YM, Boev BV (1998) Epidemiological aspects of bacterial ecology. Moscow, FarmaRus-Print.

3. McFall-Ngai M, Hadfield MG, Bosch TC, Carey HV, Domazet-Lošo T, Douglas AE, et al. Animals in a bacterial world, a new imperative for the life sciences. Proc Natl Acad Sci USA. 2013; 110(9): 3229-3236. doi: 10.1073/pnas.1218525110.

4. Meslin FX. Surveillance and control of emerging zoonoses. World Health Stat Q. 1992; 45(2-3): 200-207.

5. Bengis RG, Leighton FA, Fischer JR, Artois M, Mörner T, Tate CM. The role of wildlife in emerging and re-emerging zoonoses. Rev Sci Tech. 2004; 23(2): 497-511.

6. Pushkareva VI, Ermolaeva SA, Gintsburg AL. The role of technogenic and biological factors in spread of foodborne bacterial infections. $\mathrm{Zh}$ Mikrobiol Epidemiol Immunobiol. 2014; (5): 111-118.

7. Korenberg EI. Origin of pathogens causing infections with natural focality. Priroda. 2006; (10): 33-40.

8. Litvin V. Ecological and epidemiological aspects of the random parasitism of pathogenic bacteria. Zh Mikrobiol Epidemiol Immunobiol. 1986; (1): 85-91.

9. Kwaik YA. Invasion of mammalian and protozoan cells by Legionella pneumophila. Subcell Biochem. 2003; 33: 383-410.

10. Loutet SA, Valvano MA. A decade of Burkholderia cenocepacia virulence determinant research. Infect Immun. 2010; 78(10): 4088100. doi: 10.1128/IAI.00212-10.

11. Timchenko N, Eliseikina M, Bulgakov V, Bulakh E, Yasnetskaya E, Nedashkovskaya E, et al. Yersinia pseudotuberculosis, its toxins and plant cells. Adv Exp Med Biol. 2003; 529: 169-171.

12.Zaytseva E, Ermolaeva S, Somov GP. Low genetic diversity and epidemiological significance of Listeria monocytogenes isolated from wild animals in the far east of Russia. Infect Genet Evol. 2007; 7(6): 736-742.

13. Yoshida T, Sugimoto $\mathrm{T}$, Sato M, Hirai K. Incidence of Listeria monocytogenes in wild animals in Japan. J Vet Med Sci. 2000; 62(6): 673-675.

14. Habyarimana F, Al-Khodor S, Kalia A, Graham JE, Price CT, Garcia MT, et al. Role for the Ankyrin eukaryotic-like genes of Legionella pneumophila in parasitism of protozoan hosts and human macrophages. Environ Microbiol. 2008; 10(6): 1460-1474. doi: 10.1111/j.1462-2920.2007.01560.x.

15. Pushkareva VI, Ermolaeva SA. Listeria monocytogenes virulence factor Listeriolysin 0 favors bacterial growth in co-culture with the ciliate Tetrahymena pyriformis, causes protozoan encystment and promotes bacterial survival inside cysts. BMC Microbiol. 2010; 10: 26. doi:10.1186/1471-2180-10-26. 